\title{
Rapid diagnosis of anaerobic infections by gas-liquid chromatography
}

\author{
S. LADAS, G. ARAPAKIS, H. MALAMOU-LADAS, G. PALIKARIS, AND \\ A. ARSENI \\ From the Research Unit of the Professorial Department of Medicine, 'Evangelismos' Hospital, Athens, \\ and the Bacteriological Laboratory, Children's Hospital, 'Aghia Sophia', Athens, Greece
}

SUMMARY It was postulated that the short chain fatty acids (SCFA) produced by anaerobic bacteria might serve as microbial markers in purulent material. Eighteen pus specimens from various sources were analysed by gas-liquid chromatography (GLC), and the SCFA detected were compared with the microorganisms isolated by conventional methods. It was found that the detection of propionic, isobutyric, butyric, or isovaleric acids by direct GLC of pus specimens is strong evidence for anaerobic infection but not specific for Bacteroides fragilis. It was also shown that the presence of succinic acid in pus specimens does not necessarily indicate infection by anaerobes. It can be concluded that direct GLC of purulent material provides a rapid and reliable presumptive method for the differentiation between anaerobic and aerobic infections.

Since certain anaerobic infections may be fulminating, the need for early diagnosis is mandatory. In these cases, effective treatment depends on the recognition of the aetiological agent in the bacteriology laboratory. This is time-consuming, even in the best bacteriological hands, because clinical specimens treated by conventional methods require about one week for complete identification of the isolated strains (Gorbach and Bartlett, 1974).

The production of short-chain fatty acids (SCFA) is a known metabolic activity of anaerobic bacteria, and it is used in vitro for taxonomic purposes (Moore, 1970; Holdeman et al., 1977). Such end products can be detected in clinical specimens by gas-liquid chromatography (GLC) and can be used as a presumptive test for the diagnosis of anaerobic infections (Gorbach et al., 1974; Gorbach et al., 1976; Phillips et al., 1976; Nord, 1977). In addition, Gorbach et al. $(1974,1976)$ and Nord (1977) support the view that the detection of significant amounts of either isobutyric, butyric, or succinic acids by GLC in purulent material is strong evidence of anaerobic infection, notably by Bacteroides fragilis. On the other hand, Phillips et al. (1976) believe that specific identification of anaerobes present in purulent material is not possible by GLC.

Received for publication 17 April 1979
In view of this controversy, we decided to analyse by GLC pus specimens from various sources. The detected SCFA from each specimen were compared with the microorganisms isolated by conventional bacteriological methods.

\section{Material and methods}

\section{SPECIMENS}

Eighteen samples of pus from patients suffering from a variety of superficial and deep infections were included in the study: namely, peritonitis (6), subphrenic abscess (1), buttock gangrene (1), perirectal abscess (1), pilonidal sinus abscess (1), compound comminuted fractures of tibia with abscess formation (1), brain abscess (1), buttock abscess caused by intramuscular injections (3), and abdominal fistula (3).

Each specimen was taken with an air-sealed syringe and subsequently divided into four samples. The first one (a few drops) was used for Gram staining. The second $(0.5 \mathrm{ml})$ was inoculated into a $45-\mathrm{ml}$ culture bottle containing Peptone Broth II (BectonDickinson, Rutherford, New Jersey 07070, USA), which was immediately placed in an incubator set at $37^{\circ} \mathrm{C}$. The third sample $(0.2 \mathrm{ml})$ was transported to the bacteriology laboratory in a Port-A-Cul vial (BBL, Cockeysville, Maryland 21030, USA) within a few hours of collection and was used for anaerobic and aerobic cultures. The remaining pus $(3 \mathrm{ml})$ was 
put into an ice-cold tube and was used for direct GLC.

\section{BACTERIOLOGICAL STUDIES}

Each pus specimen was cultured on the following media: (1) Three freshly prepared Columbia human blood agar plates for incubation in aerobic, aerobic with $10 \%$ carbon dioxide, and anaerobic with $10 \%$ carbon dioxide atmosphere (Gas Pak anaerobic system, BBL); (2) Columbia human blood agar plate containing $0.1 \mathrm{mg} / \mathrm{ml}$ neomycin sulphate for anaerobic incubation (Willis, 1977); (3) McConkey's agar as enteric differential medium (Finegold et al., 1977); (4) Chapman's agar; and (5) Sabouraud's agar. All plates were incubated at $37^{\circ} \mathrm{C}$ and were examined at 24 and 48 hours. The incubation of primary anaerobic plates was continued for 96 hours.

Anaerobic bacteria were identified by the use of the API-20 anaerobe system (La Balme Les Grottes, 38390 Moltalieu Vercieu, France) and by SCFA analysis by GLC according to Holdeman et al. (1977).

Strains belonging to Enterobacteriaceae were identified biochemically by the API-20 Enterobacteriaceae system (La Balme Les Grottes, 38390 Moltalieu Vercieu, France).

The Phadebact Streptococcus Test (Pharmacia Diagnostics, Uppsala, Sweden) and the Lancefield precipitation method (Lancefield, 1933) were used for the grouping of beta-haemolytic streptococci.

\section{GAS-LIQUID CHROMATOGRAPHY}

Hewlett Packard model 5750 G research chromatograph equipped with a thermal contactivity detector was used for the SCFA analysis. The operating conditions were: injection port temperature $140^{\circ} \mathrm{C}$, column temperature $120^{\circ} \mathrm{C}$, detector block temperature $120^{\circ} \mathrm{C}$, bridge current 150 milliamps, attenuation 1, and helium carrier gas of chromatographic grade purity at a flow rate of $120 \mathrm{ml} / \mathrm{min}$.
The stainless steel chromatographic columns ( 6 feet long $\times \frac{1}{4}$ inch diameter) contained $5 \%$ Carbowax $20 \mathrm{M}$ on Chromosorb G-AWDMCS, 60-80 mesh (Hewlett Packard). Chromatographic deflections were visualised on a Hewlett Packard strip chart recorder, model $7127 \mathrm{~A}$, with an operating speed of $0.25 \mathrm{in} / \mathrm{min}$.

Titrated aqueous solutions of SCFA were diluted in human sterile ascitic fluid, to prepare the control solution, which contained $0.05 \mathrm{mEq} / \mathrm{ml}$ of each of the following acids: acetic, propionic, isobutyric, butyric, isovaleric, valeric, caproic, lactic, and succinic. Samples from this solution were extracted and chromatographed to obtain the standard values. The minimum detectable quantities of each one of the above-mentioned acids were: $4 \cdot 2,4 \cdot 2,0 \cdot 7,3 \cdot 5$, $0.3,0.9,1.9,1.2$, and $0.8 \mu \mathrm{mol} / \mathrm{ml}$ respectively.

Pus specimens were prepared for GLC as described by Nord (1977). In cases where the chromatogram showed the presence of acetic acid only, the ether extract was concentrated by gentle evaporation in a waterbath set at $40^{\circ} \mathrm{C}$. The residual volume of the ether extract was usually $0 \cdot 2-0 \cdot 1 \mathrm{ml}$ and was subsequently rechromatographed, but after that manoeuvre we were not able to perform quantitative measurements, since, by warming the ether extract, some of the diluted SCFA was lost. In this way the sensitivity of the method was increased up to 20-fold (Fig. 1: Compare chromatograms (a) and (c)). If there were still no detectable SCFA the incubated Peptone Broth II culture was used for successive chromatograms every 24 hours.

\section{Results}

Analysis of purulent material by GLC showed the presence of a number of SCFA. As can be seen from the Table, specimens from cases 1 to 12 which yielded anaerobic bacteria showed a series of volatile acids. Thus, butyric ac:d was present in all the 12 specimens, isobutyric in 10 , propionic and
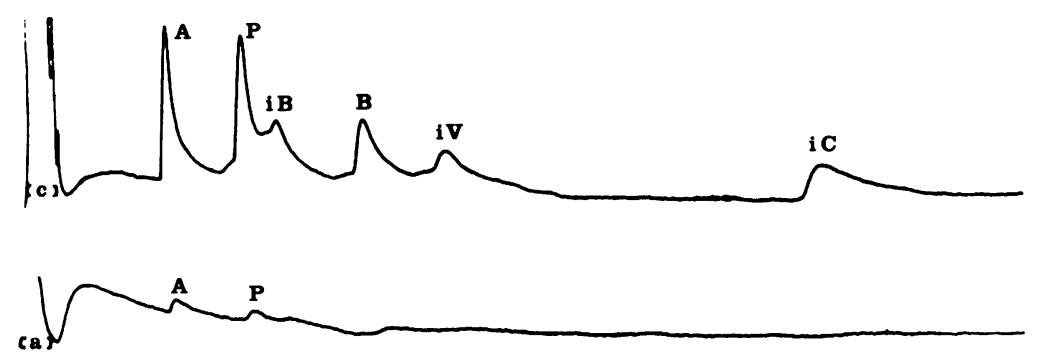

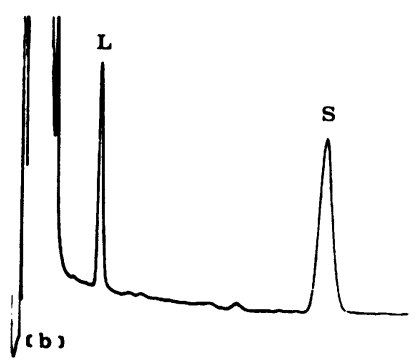

Fig. 1 Chromatographic recordings of (a) SCFA and (b) methyl esters analysis from pus specimen from case 7 (Table); (c) SCFA analysis from the same pus specimen after condensation of the original ether extract. 
Table SCFA and microorganisms detected in 18 pus samples

\begin{tabular}{|c|c|c|c|c|}
\hline \multirow[t]{2}{*}{ Case } & \multirow[t]{2}{*}{ Source } & \multirow[t]{2}{*}{ Short chain fatty acids } & \multicolumn{2}{|l|}{ Culture } \\
\hline & & & Aerobes & Anaerobes \\
\hline 1 & Peritonitis & $\mathbf{A}, \mathbf{P}, \mathrm{iB}, \mathbf{B}, \mathbf{L}$ & E. coli & $\begin{array}{l}\text { B. fragilis spp fragilis } \\
\text { Pc. asaccharolyticus }\end{array}$ \\
\hline 2 & Peritonitis & $\mathbf{A}, \mathbf{P}, \mathrm{iB}, \mathbf{B}, \mathrm{iV}, \mathbf{L}, \mathbf{S}$ & $\begin{array}{l}\text { E. coli } \\
P . \text { fluorescens }\end{array}$ & $\begin{array}{l}\text { B. fragilis spp vulgatus } \\
\text { F. species } \\
\text { Gram-negative anaerobic diplococcus }\end{array}$ \\
\hline 3 & Peritonitis & $\mathbf{A}, \mathbf{P}, \mathrm{iB}, \mathbf{B}, \mathrm{iV}, \mathbf{L}, \mathbf{S}$ & $\begin{array}{l}\text { E. coli } \\
\text { K. pneumoniae }\end{array}$ & $\begin{array}{l}\text { B. fragilis spp fragilis } \\
\text { F. nucleatum }\end{array}$ \\
\hline 4 & Peritonitis & $A, P, i B, B, i V, i C, L, S$ & $\begin{array}{l}\text { E. coli } \\
\text { Pr. mirabilis }\end{array}$ & $\begin{array}{l}\text { B. fragilis spp fragilis } \\
\text { Ps. anaerobius }\end{array}$ \\
\hline 5 & Peritonitis & $\mathbf{A}, \mathbf{P}, \mathrm{iB}, \mathbf{B}, \mathrm{iV}, \mathrm{L}, \mathrm{S}$ & $\begin{array}{l}\text { E. coli } \\
\text { K. pneumoniae } \\
\text { Str. group D }\end{array}$ & $\begin{array}{l}\text { B. fragilis spp fragilis } \\
\text { Eu. lentum } \\
\text { Pc. asaccharolyticus }\end{array}$ \\
\hline 6 & Peritonitis & $A, P, i B, B, i V, L, S$ & $\begin{array}{l}\text { E. coli } \\
\text { Str. group D }\end{array}$ & $\begin{array}{l}\text { B. fragilis spp vulgatus } \\
\text { Peptostreptococcus species }\end{array}$ \\
\hline 7 & Subphrenic abscess & $\mathbf{A}, \mathbf{P}, \mathrm{iB}, \mathbf{B}, \mathrm{iV}, \mathrm{iC}, \mathbf{L}, \mathbf{S}$ & $\begin{array}{l}\text { Str. group G } \\
\text { Str. group F }\end{array}$ & $\begin{array}{l}\text { B. melaninogenicus spp asaccharolyticus } \\
\text { Eu. lentum } \\
\text { Ps. anaerobius }\end{array}$ \\
\hline 8 & Buttock gangrene & $\mathbf{A}, \mathbf{P}, \mathbf{B}, \mathrm{iV}, \mathbf{L}, \mathbf{S}$ & $\begin{array}{l}\text { E. coli } \\
\text { Pr. mirabilis } \\
\text { Str. group D } \\
\text { Candida species }\end{array}$ & $\begin{array}{l}\text { B. fragilis spp vulgatus } \\
F . \text { nucleatum }\end{array}$ \\
\hline 9 & Perirectal abscess & $A, i B, B, i V, L, ~ S$ & & $\begin{array}{l}\text { B. melaninogenicus spp asaccharolyticus } \\
\text { Pc. magnus }\end{array}$ \\
\hline 10 & Pilonidal sinus abscess & $\mathbf{A}, \mathbf{B}, \mathbf{V}, \mathbf{L}, \mathbf{S}$ & $\begin{array}{l}\text { Staph. aureus } \\
\text { Str. group D }\end{array}$ & $\begin{array}{l}\text { B. melaninogenicus } \\
\text { Peptostreptococcus species }\end{array}$ \\
\hline 11 & $\begin{array}{l}\text { Gas gangrene after com- } \\
\text { pound fracture of tibia }\end{array}$ & $\mathbf{A}, \mathrm{iB}, \mathbf{B}, \mathrm{iV}, \mathbf{L}, \mathbf{S}$ & $\begin{array}{l}\text { Staph. aureus } \\
K . \text { pneumoniae } \\
\text { Streptococcus }\end{array}$ & Cl. sporogenes \\
\hline 12 & Brain abscess & $\mathbf{A}, \mathbf{P}, \mathrm{iB}, \mathbf{B}, \mathbf{L}, \mathbf{S}$ & & Gram-positive anaerobic coccus \\
\hline 13 & Buttock abscess & $\mathbf{A}, \mathbf{L}, \mathbf{S}$ & Staph. aureus & \\
\hline 14 & Buttock abscess & $\mathbf{A}, \mathbf{L}, \mathbf{S}$ & Staph. aureus & \\
\hline $\begin{array}{l}15 \\
16\end{array}$ & Buttock abscess & $\mathbf{A}, \mathbf{L}, \mathbf{S}$ & Staph. aureus & \\
\hline $\begin{array}{l}16 \\
17\end{array}$ & $\begin{array}{l}\text { Abdominal fistula } \\
\text { Abdominal fistula }\end{array}$ & $\mathbf{L}$ & $\begin{array}{l}\text { Pr. mirabilis } \\
\text { E. coli } \\
\text { Pr. mirabilis } \\
\text { K. pneumoniae }\end{array}$ & \\
\hline 18 & Abdominal fistula & $\mathbf{A}, \mathbf{L}, \mathbf{S}$ & $\begin{array}{l}\text { E. coli } \\
\text { Ps. aeruginosa } \\
\text { K. pneumoniae }\end{array}$ & \\
\hline
\end{tabular}

A, acetic; P, propionic; iB, isobutyric; B, butyric; iV, isovaleric; V, valeric; iC, isocaproic; L, lactic; S, succinic.
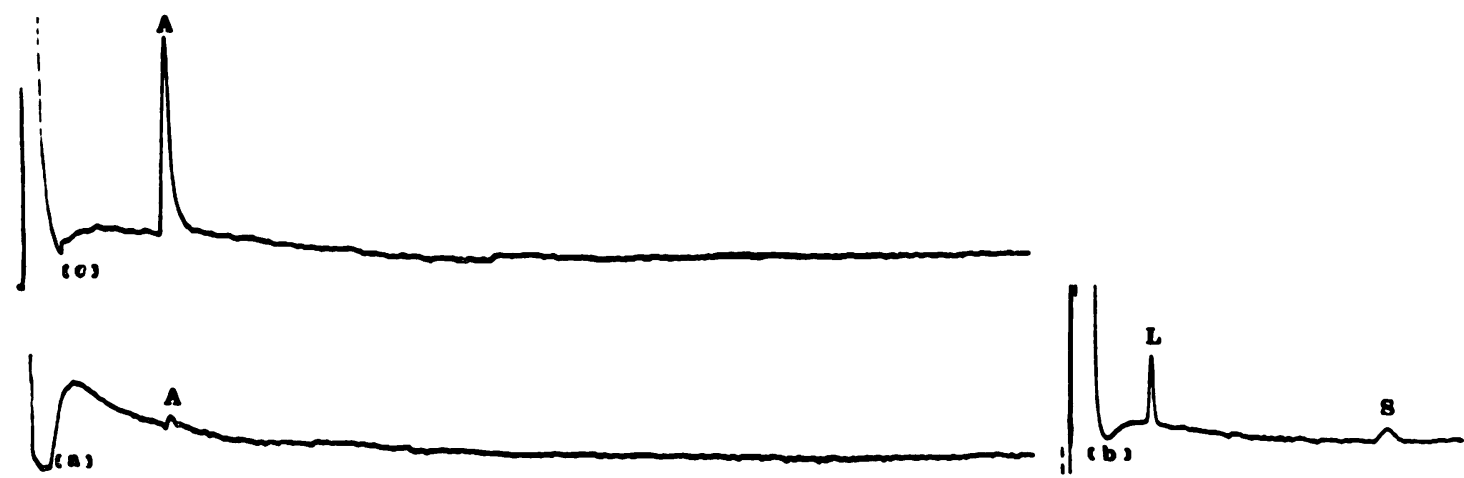

Fig. 2 Chromatographic recordings of SCFA analysis (a) before and (c) after condensation of the ether extract, as well as (b) methyl esters analysis from pus specimen from case 13 (Table).

isovaleric in nine, while valeric acid was detected in one case and isocaproic in two. On the other hand, specimens from cases 13 to 18 , which did not yield anaerobic bacteria but only aerobic, did not show any one of the above-mentioned SCFA. However, all the 18 specimens showed lactic acid, 16 showed 
acetic, and 15 succinic acid. It seems, therefore, that the presence of either propionic, isobutyric, butyric, or isovaleric acid suggests the existence of anaerobes in a pus specimen. This becomes evident when comparing the chromatographic patterns in Figures 1 and 2. Figure 1 shows chromatographic patterns of (a) SCFA and (b) methyl esters analysis from the pus specimen from case 7 (Table). Chromatographic pattern (c) is an analysis of SCFA from the same pus specimen after condensation of the original ether extract. Pattern (a) shows the presence of propionic acid, while pattern (c) shows propionic, isobutyric, butyric, isovaleric, and isocaproic acids. Culture of this pus specimen yielded Bacteroides melaninogenicus, Eubacterium lentum, and Peptostreptococcus anaerobius. On the other hand, in Fig. 2, SCFA analysis before (a) and after (c) concentration, as well as methyl esters analysis (b) shows acetic, lactic, and succinic acids. Cultures from this pus specimen (case 13) did not yield anaerobes. The only isolated bacterium was Staphylococcus aureus.

Examination of Gram-stained slides of the 18 purulent materials revealed Gram-negative bacilli in 14 cases, Gram-positive cocci in 11, Gram-positive bacilli in three cases, and Gramnegative diplococci and oval yeast-like forms in one case respectively.

Cultures of the purulent materials from cases 1 to 12 yielded anaerobic and aerobic bacteria in each specimen, while cultures of the pus specimens from cases 13 to 18 yielded only aerobes (Table). Thus $B$. fragilis subspecies were found in seven specimens, $B$. melaninogenicus subspecies in three specimens, and Fusobacterium species in three cases, while clostridium was found in only one specimen and Eubacterium lentum in two specimens. All the above anaerobes coexisted with anaerobic cocci such as Peptococcus asaccharolyticus, Peptococcus magnus, and Peptostreptococcus anaerobius.

\section{Discussion}

In recent years, anaerobic bacteria have been implicated in a wide range of infective diseases such as intra-abdominal and pelvic sepsis, aspiration pneumonia and pneumonia secondary to obstructive process, lung, brain, liver, subphrenic, and perirectal abscesses as well as endocarditis and septicaemia (Gorbach and Bartlett, 1974). Because most of these infections are fulminating and often fatal without early and proper antibiotic treatment, rapid recognition of the infective agent is imperative. However, anaerobes are not only slow-growing organisms but they almost always coexist with aerobes, especially in purulent material. In addition, many anaerobes require specialised anaerobic techniques such as glove box and roll tube. Thus, the isolation and identification of an anaerobic bacterium is laborious and takes at least one week. Therefore, the detection of SCFA from pus specimens by the use of GLC is a very helpful screening technique for the presumptive diagnosis of anaerobic infections because of its rapidity and simplicity.

Using this method we were able to inform the clinician of the nature of the infection 1 hour after the sample had reached the laboratory. In addition, like Phillips et al. (1976) and Gorbach et al. (1976), we had no false-positive results. However, we occasionally obtained false-negative chromatograms, but this we attributed to our less sensitive thermal conductivity detector. By warming the ether extracts in a waterbath we were able to obtain concentrated solutions up to 20 -fold. Samples from these extracts did not give false-negative results, apart from case 12 . That was a brain abscess which had been treated intensively with antibiotics for 20 days before incision. The Gram-stained slides from the original pus specimen examined by direct microscopy showed scanty Gram-positive cocci which were grown in pure culture but they were not identified. SCFA analysis of an original pus sample, as well as a concentrated ether extract solution, did not visualise any fatty acid on the chart. However, SCFA analysis of a sample from the incubated Peptone broth II at 48 hours showed the existence of propionic, isobutyric, and butyric acids. It seems certain that the bacterium was an anaerobic Gram-positive coccus whose multiplication had been greatly reduced by the antibiotic treatment.

A comparison of the bacteriological studies with the SCFA analysis reveals that acetic and lactic acids are not specific for the diagnosis of anaerobic infection. Gorbach et al. $(1974,1976)$ and Nord (1977) have claimed that the detection of succinic acid is strong evidence for the existence of anaerobes, notably $\boldsymbol{B}$. fragilis, in pus specimens. Nevertheless, in specimens from cases $13,14,15$, and 18 we detected succinic acid $(2 \cdot 1,3,1 \cdot 4$, and $1 \cdot 7 \mu \mathrm{mol} / \mathrm{ml}$ respectively) but we failed to isolate anaerobes. It seems certain, therefore, that succinic acid is not specific for the diagnosis of anaerobic infections. Besides, it is known (Nord, 1977) that the end products of glucose metabolism from Escherichia coli, Klebsiella pneumoniae, and Proteus mirabilis include succinic acid. In our experience, Staphylococcus aureus also produces succinic acid in vivo (Table: cases 13, 14, 15) (Fig. 2b) and in vitro. However, propionic, isobutyric, butyric, and isovaleric acids were recorded in almost every chromatogram from pus samples which yielded different species of anaerobes.

In conclusion, the data presented here are in 
agreement with those reported by Phillips et al. (1976) and indicate that the detection of propionic, isobutyric, butyric, or isovaleric acids by direct GLC of purulent material is strong evidence for anaerobic infection but not specific for $B$. fragilis. In addition, we obtained evidence that the detection of succinic acid by GLC does not necessarily indicate infection by anaerobes.

Since an early report from the bacteriology laboratory is of much greater clinical value than a definite taxonomic report one week later, it must be stressed that direct GLC of pus specimens is very useful because it can almost always set the diagnosis of anaerobic infection.

\section{References}

Finegold, S. M., Shepherd, W. E., and Spaulding, E. H. (1977). Practical Anaerobic Bacteriology (Cumitech, 5). American Society for Microbiology, Washington, D.C. Gorbach, S. L., and Bartlett, J. G. (1974). Anaerobic infections. New England Journal of Medicine, 290, 1177-1184, 1237-1245, 1289-1294.

Gorbach, S. L., Mayhew, J. W., Bartlett, J. G., Thadepalli, H., and Onderdonk, A. B. (1974). Rapid diagnosis of Bacteroides fragilis infections by direct gas-liquid chromatography of clinical specimens (Abstract). Clinical Research, 22, 442A.
Gorbach, S. L., Mayhew, J. W., Bartlett, J. G., Thadepalli, H., and Onderdonk, A. B. (1976). Rapid diagnosis of anaerobic infections by direct gas-liquid chromatography of clinical specimens. Journal of Clinical Investigation, 57, 478-484.

Holdeman, L. V., Cato, E. P., and Moore, W. E. C. (1977). Anaerobe Laboratory Manual. Virginia Polytechnic Institute and State University Anaerobe Laboratory, Blacksburg, Virginia.

Lancefield, R. C. (1933). A serological differentiation of human and other groups of hemolytic streptococci. Journal of Experimental Medicine, 57, 571-595.

Moore, W. E. C. (1970). Relationships of metabolic products to taxonomy of anaerobic bacteria. International Journal of Systematic Bacteriology, 20, 535-538.

Nord, C. E. (1977). Diagnosis of anaerobic infections by gas-liquid chromatography. Acta Pathologica et Microbiologica Scandinavica, Supplement 259B, 55-59.

Phillips, K. D., Tearle, P. V., and Willis, A. T. (1976). Rapid diagnosis of anaerobic infections by gas-liquid chromatography of clinical material. Journal of Clinical Pathology, 29, 428-432.

Willis, A. T. (1977). Anaerobic Bacteriology: Clinical and Laboratory Practice, 3rd edition. Butterworths, London, Boston.

Requests for reprints to: Dr S. Ladas, Research Unit of the Professorial Department of Medicine, 'Evangelismos' Hospital, Athens, Greece. 